\title{
"ENTRE LA ESTIGMATIZACIÓN Y LA RESTRICCIÓN". POLÍTICAS MIGRATORIAS Y DISCURSOS POLÍTICOS SOBRE FAMILIA, MIGRACIÓN, GÉNERO Y GENERACIÓN \\ EN PAÍSES DE INMIGRACIÓN Y EMIGRACIÓN: ESPAÑA Y COLOMBIA $^{1}$
}

MARIA MARGARITA ECHEVERRI BURITICÁ* País: Colombia - España Fecha de nacimiento: Mayo 7 de 1970

Documento de Identidad: C.C. 39784114

Afiliación Institucional: Docente Facultad de Psicología, Pontificia Universidad Javeriana Bogotá. Integrante co-fungotá Grupo Interdisciplinario de Investigadoras Migrantes (GIIM)

Nivel de escolaridad: Doctora en Ciencias Políticas y Sociología. Facultad de Ciencias Políticas y Sociología de la Universidad Complutense de Madrid.

CLAUDIA PEDONE**

País: Argentina - España

Fecha de nacimiento

22/11/1966

Documento de Identidad: X2429173M

Afiliación Institucional: Directora del Área de Migración del CIIMU (Institu de l'Infància i Món Urbà de Barcelona). Integrante cofundadora Grupo Interdisciplinario de Investigadoras Migrantes (GIIM).

Nivel de escolaridad: Doctora en Geografía Humana por la Universidad Autónoma de Barcelona.

SANDRA GIL ARÁUJO*** País: Argentina - España Fecha de nacimiento: 14 de enero de 1964

Documento de Identidad: 17020547

Afiliación Institucional: Investigadora titular de CONICET con sede en el Instituto Gino German de la Facultad de Ciencias Sociales de la Universida de Buenos Aires. Inter de Buenos Aires. Integrante co-fundadora Grupo Interdisciplinario de Investigadoras Migrantes (GIIM)

Nivel de escolaridad: Doctora en Sociología. Facultad de Ciencias Políticas y Sociología de la Universida Complutense de Madrid

Artículo de Revisión según clasificación de Colciencias.

${ }^{1}$ El artículo está basado en la ponencia "Entre la estigmatización, la restricción y matización, la restricción y y discursos políticos sobre familia, migración y género en contextos de emigración/ inmigración: Colombia y España: presentada en I Seminario Internacion I Seminario Internacional Contemporáneas y Políticas Públicas. Cartagena Colombia, Agosto 8, 9 y 10 de 2012.
"AMONG THE STIGMATIZATION AND THE RESTRICTION". Migration POLICIES AND POLITICAL DISCOURSES ON FAMILY, MIGRATION, GENDER AND GENERATION IN IMMIGRATION AND EMIGRATION COUINTRIES: SPAIN AND COLOMBIA

\author{
Por: María Margarita Echeverri Buriticá \\ Claudia Pedone \\ Sandra Gil Aráujo
}

Artículo Recibido: 15 septiembre 2012. Artículo Aprobado: 25 enero 2013.

\section{RESUMEN}

This article explores the ways of thinking about links between family, migration and integration - as well as gender relations across them - in Spain as a country of immigration and Colombia as a country of emigration. It offers a review of the process of how migrant families become a social problem at both ends of the migratory chain. In the European countries, over the past two decades, family reunification is no longer a right and has become a prerogative of the State, which can be accessed by meeting certain economic and cultural requirements. At the same time, in Colombia since the beginning of the 21st century and due to the increase of women migration to Europe, a social and political discourse presenting migration as producer of family breakdowns took hold. In both cases, women and the younger generations are at the core of discourses and public debates about family and migration.

After a brief introduction, the article reviews the European political and economic context in which family-related migration began to be problematized and restricted. Specifically, it deals with linkages between migration, family and gender in policies and public discourses at the State and regional level in Spain. Subsequently the case of Colombian migration is addressed. After a brief account of the latest academic publications on family migration, the text ascertains the ways of thinking about connections between migration, family, gender and generation in Colombian public policies. Finally, in the last remarks, some consequences of female migration stigmatization and restrictions for family migration on the lives of migrants and their families are highlighted.

Palabras Claves: Migrant families, family migration, migration policies, gender, Colombia, Spain. 


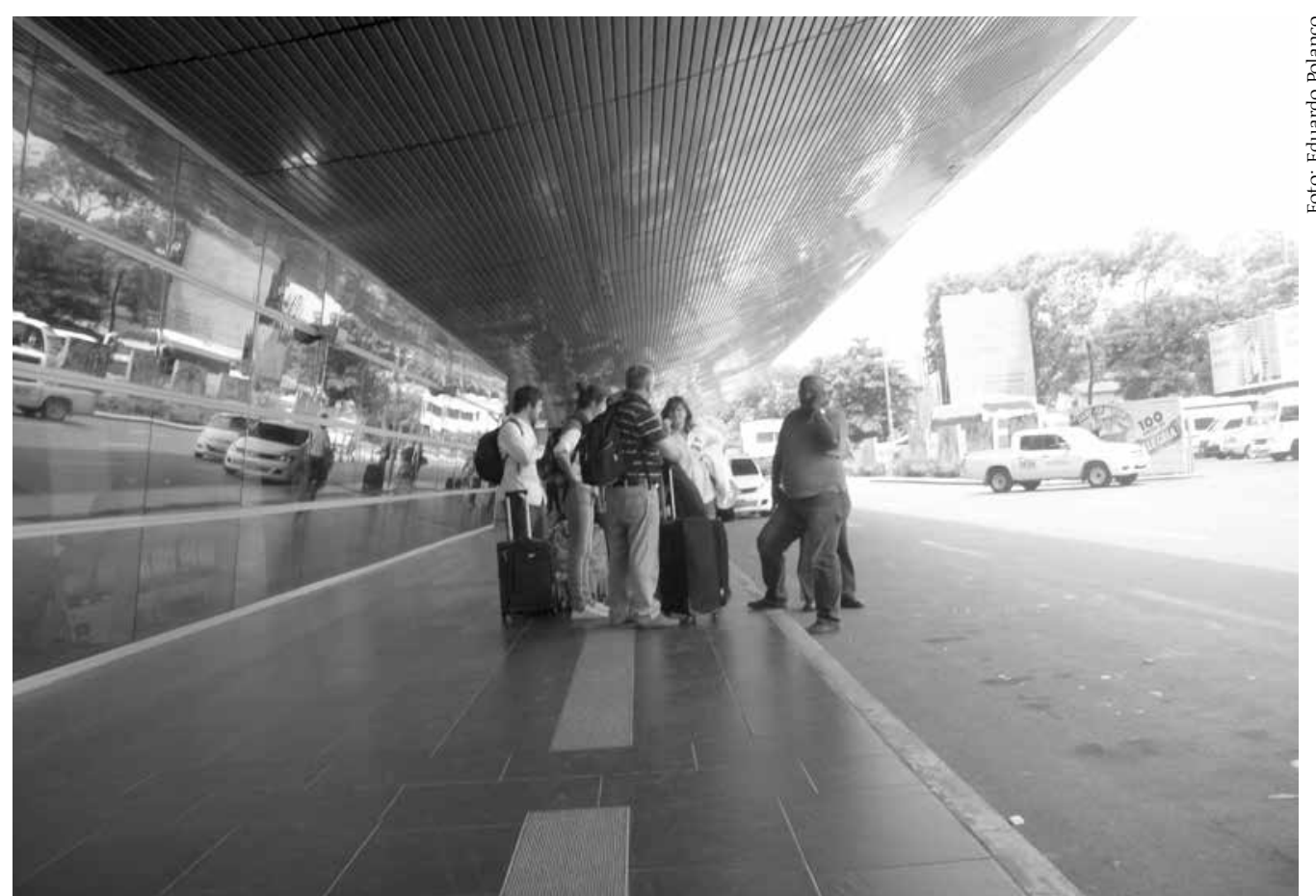

Salida y llegada 2013.

\section{ABSTRACT}

This article explores the ways of thinking about links between family, migration and integration - as well as gender relations across them - in Spain as country of immigration and Colombia as country of emigration. It offers a review of the tranzsformation process of migrant families into a social problem at both ends of the migratory chain. In the European countries, over the past two decades, family reunification is no longer a right and has become a prerogative of the State, which can be accessed by meeting certain economic and cultural requirements. At the same time in Colombia, since the beginning of the 21st century and due to the increase of women in the migration to Europe, a social and political discourse presenting migration as producer of family breakdowns took hold. In both cases, women and the younger generation are at the core of discourses and public debates about family and migration.

After a brief introduction, the article reviews the European political and economic context in which family-related migration began to be problematized and restricted. Specifically, it deals with linkages between migration, family and gender in policies and public discourses at the State and regional level in Spain. Subsequently the case of Colombia is addressed. After a brief account of the latest academic publications on family migration, the text ascertains the ways of thinking about connections between migration, family, gender and generation in Colombian public policies. Lastly, in the final remarks, some consequences of female migration stigmatization and restrictions for family migration on the lives of migrants and their families are highlighted.

Key words: Migrant families, family migration, migration policies, gender, Colombia, Spain. 


\section{INTRODUCCIÓN}

Las crecientes restricciones a la migración familiar en los países de la UE, junto a la estigmatización de la emigración de mujeres-madres en los países latinoamericanos, han convertido a las familias migrantes en problema social en ambos extremos de la cadena migratoria. En el contexto europeo, la reagrupación familiar ha dejado de ser un derecho para convertirse en una prerrogativa del Estado, a la que se puede acceder cumpliendo una serie de requisitos económicos y, ahora también, culturales (Kraler et. al., 2011). Es habitual que la justificación de las limitaciones al derecho natural de la vida en familia se vincule con las diferencias/deficiencias que cargan las familias migrantes (y sus integrantes) para alcanzar una integración exitosa en la sociedad de llegada (Gil Araujo, 2010b). Paralelamente, el aumento de la presencia femenina en las corrientes migratorias procedentes de países latinoamericanos ha generado importantes cuestionamientos a los lugares y responsabilidades tradicionalmente asignados a varones y mujeres en el ámbito de la familia. Estas transformaciones han disparado discursos en los países de origen, como Ecuador y Colombia, que suelen asociar la migración femenina con el abandono de la familia, y diagnostican diversas "disfuncionalidades" a las familias con madres migrantes (Pedone, 2008; Herrera, 2011). Ambos procesos han colocado a las familias migrantes en el centro de los debates políticos sobre las implicaciones nacionales de las migraciones internacionales, lo que ha dado lugar en ciertas ocasiones a políticas públicas dirigidas a estas familias y sus miembros, principalmente las mujeres y las generaciones más jóvenes.

Partiendo de estas constataciones, el objetivo de este artículo es explorar las formas de pensar las vinculaciones entre familia, migración e integración -y las relaciones de género que las atraviesan- en España como país de inmigración y Colombia en tanto país de emigración. Los análisis presentados se enmarcan en los resultados del proyecto "Políticas migratorias, transnacionalismo familiar y estratificación cívica. Migraciones latinoamericanas hacia España”².

${ }^{2}$ Proyecto (CSO2009-13649 Subprograma SOCI) financiado por el Plan I+D+i del Ministerio de Ciencia e Innovación español. Equipo de investigación: Claudia Pedone (IP), Sandra Gil Araujo María Margarita Echeverri y Belén Agrela. http://www. ciimu.org/pidpmi/
Nuestra propuesta metodológica enfatiza el trabajo de campo etnográfico transnacional que para este estudio se llevó a cabo entre los años 2010 y 2012 en Colombia, específicamente en el Departamento de Risaralda y en la ciudad de Bogotá, y en España, en las regiones de Madrid y Cataluña. En este marco, realizamos entrevistas en profundidad a miembros de familias migrantes en origen y a migrantes en destino, expertos, abogados, personal 
de la administración pública, técnicos/as de inmigración y miembros de ONG y asociaciones migrantes, en el ámbito estatal, autonómico y municipal. El estudio se ha complementado con la recopilación y análisis de fuentes secundarias, documentos (legislaciones, planes, informes), y las declaraciones de representantes institucionales en los medios de comunicación de referencia.

A continuación, en primer lugar se repasa el contexto económico y político europeo en el cual la migración por motivos familiares comenzó a ser problematizada y restringida. En concreto se analizan las vinculaciones entre migración, familia y género que han atravesado las políticas y los discursos públicos en el ámbito estatal y regional español. En este punto se presta especial atención a las restricciones a la migración familiar impuestas en la última reforma de la Ley de Extranjería española, así como a las prácticas administrativas, formales e informales, que en origen y en destino retrasan o impiden los procesos de reunificación familiar. Posteriormente se aborda el caso de Colombia, donde desde principios del siglo XXI, ante el incremento de la presencia femenina en la migración hacia Europa, se afianzó un discurso social y político que definía a las mujeres migrantes como responsables de la desintegración y disfuncionalidad que (supuestamente) afectaba a sus familias. Después de un breve estado de la cuestión de la reciente producción académica sobre la migración familiar colombiana, se indagan las formas de pensar las conexiones entre migración, familia, género y generación en las política públicas impulsadas desde el Estado colombiano. Por último, en las notas finales se resaltan algunas de las incidencias que las estigmatizaciones de la migración femenina y las restricciones a la migración familiar tienen en la vida de las migrantes y sus familias.

\section{POLÍTICAS Y DISCURSOS PÚBLICOS SOBRE FAMILIA, GÉNERO Y MIGRACIÓN EN ESPAÑA}

En los países europeos tradicionales receptores de inmigración, hasta mediados de los años setenta no se consideraba a la población inmigrante como un problema para el orden nacional, en tanto se suponía que los trabajadores extranjeros no se quedarían más allá de la duración de sus contratos de trabajo. Sin embargo, y contrariamente a lo que tanto gobiernos como empresarios esperaban, muchos trabajadores extranjeros rechazaron los programas de retorno implementados en el marco de la crisis económica internacional y amparados en el derecho de reagrupación familiar, trajeron a sus familias. De este modo, la reducción y definición instrumental de la migración como mano 
de obra, tolerada como mal menor pero jamás deseada, se quebró cuando se pasó a una inmigración familiar, una inmigración de poblamiento (Sayad, 2000). Si bien esta transformación era previsible de derecho, de hecho no fue prevista, constituyéndose para Sayad en el punto del que parten los discursos actuales sobre los efectos culturales de la inmigración. Desde entonces, la integración se ha convertido en la forma más común de conceptualizar el desarrollo de las relaciones entre las viejas naciones europeas y su creciente población inmigrante no europea (Gil Araujo, 2010a).

Ante el cierre de fronteras a la migración laboral, la migración por motivos familiares se constituyó en la principal y casi única vía de ingreso regular a los países del centro y norte de Europa, superando a las solicitudes de asilo. En las últimas décadas, ante la persistencia de estos ingresos, la migración familiar ha sido objeto de continuas restricciones y exigencias, primero económicas y posteriormente de tipo lingüístico y cultural en gran parte de los países de la UE (Kraler, 2010). Así, las políticas de migración familiar pensadas en los años ochenta como instrumento de integración, en la actualidad operan como herramienta de control, restricción y selección de inmigrantes (Gil Araujo, 2010b).

En general, en los países de la UE la migración familiar ha dejado de ser un derecho, para convertirse en una decisión de carácter administrativo. En el caso de España, hasta principios del siglo XXI, las familias migrantes habían estado ausentes de las políticas y de los discursos sobre migración. Con la Ley de Extranjería 4/2000 por primera vez apareció un capítulo dedicado a la reagrupación familiar en el marco de los derechos y deberes de los/as extranjeros/as. La primera modificación de esa Ley se llevó a cabo menos de un año después de su entrada en vigor, con la Ley Orgánica 8/2000 de 22 de diciembre, que estableció un tiempo de convivencia en España durante el cual el/la cónyuge no puede desvincularse del reagrupante (dos años) y redujo la lista de reagrupables. En los procedimientos, se recuperaron las restricciones anteriores a la ley 4/2000: permiso de residencia renovado, vivienda adecuada y medios de subsistencia suficientes. Uno de los objetivos mencionados para la siguiente reforma de la Ley en 2003 fue evitar fraudes en las reagrupaciones familiares en cadena. Desde entonces, solo puede reagrupar un trabajador/a residente a título propio. Desapareció también la exención de visado para los familiares que ya se encontraran de forma irregular en España. 
Desde el comienzo de la tematización de la inmigración en términos de integración, las familias migrantes y dentro de ellas las mujeres, devinieron en objeto preferencial de intervención de las políticas públicas (Agrela, 2009). En este marco, la reunificación familiar fue concebida como una herramienta de integración de inmigrantes. Incluso, el establecimiento de requisitos económicos y una vivienda "normal" fueron justificados como un instrumento para garantizar la integración de las familias migrantes.

Así, la conexión entre género, familia y migración ha estado presente desde la filosofía de diversos planes y programas dirigidos a la integración de la población inmigrante, tanto a nivel estatal como autonómico, puestos en marcha desde mediados de los años noventa a nivel estatal, y principios de 2000 en gran parte de las autonomías y algunas ciudades (Gil Araujo, 2010a; Pedone, Agrela y Gil Araujo, 2012). A nivel estatal, en el último Plan Estratégico de Ciudadanía e Integración 2007-2010, presentado en febrero de 2007 por la Secretaría de Estado de Inmigración y Emigración, se reitera una vez más la vinculación entre reunificación familiar y proceso de integración, haciendo especial hincapié en el papel de la familia como agente "adaptador" en el ámbito escolar:

El contexto familiar influye poderosamente en la adaptación de los alumnos a la escuela y en sus posibilidades de aprendizaje. Sin embargo, factores como la precariedad económica y la mayor vulnerabilidad de las familias inmigrantes, la falta de tiempo libre suficiente, los diferentes parámetros culturales o la insuficiencia de formación o experiencia académica de los progenitores, intervienen como barreras que inciden en la baja participación de estas familias en el sistema educativo (Secretaría Estatal para la Inmigración y Emigración, 2007:146).

Las novedades más relevantes con respecto a planes anteriores son la recomendación de incluir a las familias migrantes en las acciones que faciliten la conciliación de la vida laboral y familiar, y el acompañamiento a familias transnacionales, dentro de "proyectos que contemplen el acompañamiento integral a familias con riesgo de desestructuración por la separación de sus miembros entre país de origen y de destino" (Secretaría Estatal para la Inmigración y Emigración, 2007:232).

A nivel regional, el gobierno de la Generalitat de Cataluña fue desde 1993, pionero en la elaboración de planes dirigidos a la integración de la población 
inmigrante. En el último plan autonómico, Plan de Ciudadanía e Inmigración 2009-2012, las familias migrantes se presentan como uno de los objetivos prioritarios de las políticas públicas para garantizar la integración en una cultura pública común, junto con la infancia, la juventud y las personas mayores. También se recomienda la promoción de nuevas formas de organizar los horarios y los servicios para favorecer la conciliación de la vida familiar, personal y laboral (Secretaria per a la Immigració, 2010:86) sin hacer referencia alguna al transnacionalismo familiar. En las acciones dirigidas a las mujeres migrantes se repiten algunas de las visiones hegemónicas sobre "el papel de las mujeres inmigradas como eje de integración en el ámbito escolar y familiar" y "las mujeres como puentes de cultura" (Secretaria per a la Immigració, 2010:153).

En el marco del proyecto de investigación aquí presentado, el análisis de Ana Rovetta (2011), explora las formas de pensar la conexión entre migración, familia e integración que atraviesan las políticas públicas, tomando como caso de estudio los Planes de Integración de la Comunidad de Madrid entre 2001 y 2009. En palabras de la autora: "El planteamiento que se elabora respecto a la familia inmigrante en estos planes tiene dos caras: por un lado se la considera como unidad básica para promover el proceso de adaptación de los inmigrantes; y por otro se la identifica como un nuevo reto debido a la vulnerabilidad especialmente alta de mujeres y menores. Se le otorga poder de contención psicosocial respecto a sus miembros, mientras se la asocia con situaciones de tal vulnerabilidad psicológica que rozan la patologización del colectivo" (Rovetta, 2011:2). En los últimos dos Planes la reagrupación familiar se describe como un proceso que genera tensiones y ansiedades, sin vincular estas tensiones con las crecientes dificultades que confrontan las familias migrantes para poder ejercer su derecho a vivir en familia.

La familia transnacional es concebida como una nueva realidad que puede poner en jaque al modelo familiar tradicional español. Así, mujeres y menores son definidos como los grupos vulnerables por excelencia; las mujeres por atravesar estados de desgaste emocional y los menores por padecer situaciones de desatención y desamparo. En el último Plan (2009-2012) los jóvenes emergen como un nuevo sujeto/objeto de las políticas públicas, en general visualizados como portadores de comportamientos desviados y vinculados a "bandas juveniles violentas". Desde la óptica del gobierno regional madrileño, las causas de estas desviaciones están en la desintegración de las estructuras familiares, el desarraigo y el choque cultural que parecieran ser procesos 
inherentes (casi naturales) a la experiencia migratoria (Rovetta, 2011). Como en otros terrenos de atención social a población inmigrante en la Comunidad de Madrid (Gil Araujo, 2010a), las medidas diseñadas para la intervención con las familias migrantes en los Planes de Integración apuntan a incidir en las disposiciones, comportamientos, habilidades y actitudes individuales de la población migrante (Rovetta, 2011) transformando así obstáculos jurídicos, económicos y sociales en deficiencias personales.

\subsection{CRISIS ECONÓMICA, POLÍTICAS MIGRATORIAS Y PRÁCTICAS ADMINISTRATIVAS}

En el año 2009, en el contexto de agudización de crisis económica, el Ministro de Trabajo e Inmigración español propuso recortar el derecho de reagrupación de los ascendientes (padres, madres, suegros y suegras) de la población inmigrante no comunitaria. Estas recomendaciones fueron incluidas en la última reforma de la ley, publicada en el Boletín Oficial de las Cortes Generales el 1 de julio de 2009. A partir de esta modificación solo los inmigrantes con permisos de larga duración podrán reunificar a "los ascendientes del reagrupante y de su cónyuge, en línea recta y en primer grado, cuando estén a su cargo, sean mayores de sesenta y cinco años y existan razones que justifiquen la necesidad de autorizar su residencia en España" (Proyecto de Ley Orgánica de reforma de la Ley Orgánica 4/2000 de 11 de enero, sobre derechos y libertades de los extranjeros en España y su integración social, 2000:9)³.

Las entrevistas realizadas con representantes políticos coincidieron con el debate de esta reforma. En línea con los argumentos del Partido Socialista Obrero Español (PSOE) en el gobierno, algunos de los entrevistados insistían en la necesidad de limitar a los familiares que puedan entrar en la reagrupación, para bien de los inmigrantes (facilitar la integración) y de la sociedad de inmigración.

Reunificación familiar, sí, sí, siempre ¿por qué? Pues por los derechos humanos y ya ni tan siquiera es por, por reconocimiento de derechos humanos. ¿Y por qué pondría yo limitaciones? Las pondría porque los primeros perjudicados de una apertura total serían ellos mismos y eso no lo podemos permitir porque serían doblemente víctimas de las situaciones que generan las migraciones. Los serían en país de origen y los serían en su país de recepción (Asesora PSOE, 2009).

${ }^{3}$ Si bien esta limitación a la reunificación de ascendientes fue introducida en la última reforma, los abogados entrevistados confirman que estas limitaciones se estaban aplicando en la práctica tiempo antes. 
Bueno, creo que hay que mantener la reunificación familiar en el núcleo real de lo que es familiar y suficiente para dar estabilidad al inmigrante, más allá no. Hablo de un concepto de familia que si, o sea, estrictamente el concepto occidental, podemos estirarlo un poco pero no tiene porque llegar al concepto de... Nuestro concepto de familia y la justificación en términos políticos, siendo fríos, términos políticos es porque es parte de la estabilidad del propio inmigrante, por tanto, contribuye, es humana y contribuye a la estabilidad del propio inmigrante. Cónyuges e hijos seguro, y en algunos casos padres, y a lo mejor le pondría padres de cierta edad. O sea, uno puede traer a sus padres de más de 60 años y sino, no los puede traer (CiU, Parlamento europeo, 2009).

En este marco de restricción normativa y crisis económica los procesos de reagrupación familiar se han reducido de manera drástica. Por un lado, debido a la dificultad de las migrantes para cumplir con los requerimientos de contrato de trabajo, permiso de residencia, ingresos y vivienda. Pero también por la ralentización del proceso administrativo y el incremento de las denegaciones a las solicitudes para la reagrupación, así como a las renovaciones de permisos de residencia y trabajo y las regularizaciones por arraigo. Paralelamente se hace más difícil cubrir el costo de las tasas para la realización de esos trámites, que han aumentado de modo "exponencial", como nos relata uno de los abogados entrevistados en Madrid:

El arraigo, la renovación de las tarjetas, el reconocimiento de la condición de inmigrante. La renovación, si se comete un mínimo fallo, ya es inadmitido y la persona queda para comenzar nuevamente los trámites, en estado de irregularidad y siendo objeto de las sistemáticas redadas policiales. Los trámites se han ralentizado al punto de que si, anteriormente, se resolvía una situación en tres o cuatro meses, hoy estamos hablando del doble. Pero hay una cosa curiosa, y es que la Administración ha aumentado el valor de las tasas de una manera exponencial (...) De tal manera que, todas aquellas personas que quieren renovar su tarjeta, su permiso de residencia y trabajo, le están dando a la Administración más de 200 euros (Abogado, Madrid, 2010).

Las prácticas informales y las decisiones discrecionales que dilatan, restringen o impiden los procesos de reagrupación también tienen lugar en los consulados españoles en los países de origen. Este hecho fue reportado en nuestro trabajo 
de campo en Colombia, sobre todo en los casos de las reunificaciones de padres, madres, suegros y suegras. A pesar de que los candidatos a la reunificación tengan una resolución favorable en España, es el funcionario del consulado español en Colombia quien decide si ese proceso se retrasa y/o se concreta.

Hay mucha, mucha traba en el proceso de reagrupación de los padres. Eso sí están muy complicados, porque la gente considera cuando ya tiene la resolución favorable en España, y cuando ya les dan la aprobación allá, que aquí les van a aprobar. Y realmente, en los padres es muy complicado tanto en el régimen comunitario como en el régimen general. Muy complicado. Es realmente muy poco lo que están aprobando. Porque a la gente le piden, pues, por cualquier cosa le niegan, porque si tiene más familia, porque no se concibe, como la ley dice que existan razones que justifiquen la reagrupación, eso, existir razones que justifiquen es muy, va a discrecionalidad de los consulados. Es muy discrecional del funcionario quien [decide] quien puede o no puede hacerlo. Entonces es muy complicado porque es discrecional. Yo veo mucha debilidad en la reagrupación de los padres (Técnica en ONG que trabaja con migrantes, Pereira, Colombia, 2010).

Actualmente a estas prácticas informales y discrecionales que obstaculizan los procesos de reagrupación familiar, se suman las solicitudes de pruebas de ADN y pruebas densométricas, realizadas a "algunas familias migrantes" para la estimación de la edad y el vínculo de parentesco para los menores extranjeros documentados o no, y extendidas a ciertos familiares adultos con carga genética coincidente "cuando los documentos registrales no ofrecen la suficiente veracidad", que contribuyen a gestar nuevos factores de vulnerabilidad para estas familias ${ }^{4}$. Se ponen en cuestión los vínculos legales o sanguíneos entre padres e hijos, abuelos y nietos y en ocasiones entre hermanos. Esta práctica no cuenta con previsión legal en la normativa de extranjería española, ni en el desarrollo reglamentario, por ello su alto riesgo de arbitrariedad desestabiliza la protección de los derechos fundamentales y las garantías mínimas del no nacional, sometiéndolo a un trato discriminatorio (La Spina, 2012) . $^{5}$

Paralelamente, en los contextos de origen de la migración latinoamericana, el aumento de la presencia femenina en las corrientes migratorias que llegan a España ha dado lugar a la emergencia de "nuevas" problematizaciones del vínculo entre familia, migración, género y generación. Como veremos a continuación, al igual que en el contexto español, las mujeres y las

${ }^{4}$ El coste de las pruebas que son cubiertas por los solicitantes (migrantes) asciende a los $300 €$ y los resultados no son inmediatos.

${ }^{5}$ En nuestra investigación, también llevada a cabo en Ecuador, Brasil y República Dominicana hemos encontrado este tipo de prácticas hacia las familias migrantes dominicanas. Algunos testimonios indican que como requisito para la reagrupación de hijos e hijas se ha exigido no sólo las pruebas de ADN, sino también pruebas densométricas, ya que las primeras no eran suficientes para comprobar el vínculo materno con sus hijas (Notas de trabajo de campo, Barcelona, 2011). 
${ }^{6}$ La migración de América Latina hacia España se ha distinguido por una predominancia de mujeres, que se mantuvo en crecimiento hasta el periodo 1992-1996. En aquel momento, $62 \%$ de la migración latinoamericana era femenina. Posteriormente la prepor derancia de mujeres alcanzó porcentajes más moderados, con un $53 \%$ en el periodo 2002-2006. Más tarde, a raíz de las cadenas migratorias y las reunificaciones familiares, se registró un los sexos. Sin embargo, exislos sexos. Sin embargo, exis-
ten importantes diferencias en relación a los países de origen. Los grupos más feminizados son, por un lado, los que han llegado hace menos tiempo: Paraguay men tiempo: Paraguay (60\%) y Bolivia (55\%), pero también algunos ya estabilizados, como República Dominicana, Colombia y Cuba (en torno al 55\% son mujeres). Por el contrario,

Perú, Ecuador, Argentina,

Chile y Uruguay muestran un mayor equilibrio entre varones y mujeres. generaciones jóvenes componen el núcleo central de los discursos y debates públicos sobre las familias migrantes en Colombia.

\section{POLÍTICAS Y DISCURSOS SOBRE MIGRACIÓN Y FAMILIA EN LOS CONTEXTOS DE EMIGRACIÓN: EL CASO DE COLOMBIA}

El inicio del siglo XXI marcó un punto de inflexión en relación a la intensidad, aceleración y feminización de los flujos migratorios latinoamericanos hacia España. Para el caso de la población proveniente de Colombia, según datos de la Encuesta Nacional de Inmigrantes (ENI, 2007), el 67\% de los y las colombianas que han migrado a España entraron entre 1997 y 2001 y las mujeres representan el 60\% de la población para esa época (Actis, 2009) Fueron estas mujeres colombianas igualmente, los primeros eslabones de las cadenas migratorias (Pedone, 2006), quienes según un estudio de UNINSTRAW/OIM (2007) realizaron un proceso de reagrupación familiar informal de sus cónyuges e hijos especialmente, que se aceleró tras el anuncio de la obligatoriedad del visado para la población colombiana que entraría en vigor a partir del año 2002. En pocas semanas se planearon y llevaron a cabo procesos de reagrupación familiar informales -como turistas-, a pesar de la situación jurídica irregular, el poco tiempo de residencia y la precariedad laboral, en tanto más adelante se tornaría más complicado cruzar la frontera. A partir del año 2002, tras la imposición del visado y las restricciones a la migración familiar que se fueron incorporando, los ingresos descendieron pero no se frenaron completamente. En algunos casos se privilegiaron procesos de reagrupación familiar autónomos por la vía de los contingentes de trabajo. A partir de entonces la reagrupación familiar pasó a ser la vía de migración que prevalece para la población colombiana hacia España (Sanabria, 2008), con un incremento de la presencia de niños, niñas y jóvenes migrantes, que consolida proyectos migratorios familiares (Cachón, 2003) con una significativa tendencia al asentamiento (UN-INSTRAW/OIM, 2007).

Aunque la feminización de la emigración colombiana hacia España con proyectos migratorios familiares evidentes, es un intenso proceso que se da desde hace más de una década, en Colombia el tratamiento de la migración familiar en el discurso público, institucional y académico es reciente e incipiente. Si bien en la última década el abordaje académico del proceso migratorio se ha incrementado de manera significativa, las investigaciones en su mayoría han puesto el acento en la caracterización general de la población con base en el perfil socioeconómico, la inserción en el mercado laboral, 
las condiciones de trabajo y la transformación de la migración desde una perspectiva cuantitativa y territorial (Aparicio y Giménez, 2003; Cárdenas y Mejía, 2006; Garay, 2006; Guarnizo, 2006; Garay y Medina, 2007; Khoudour, 2007). El marcado énfasis y la intensa producción de investigaciones sobre las remesas (Garay y Rodríguez, 2005; ASOCAMBIARIA, 2004; OIM y DANE, 2005; OIM, 2007) y los seminarios que se han realizado para debatir el tema (OIM, 2005; Ministerio de Relaciones Exteriores, 2006), reflejan el modo en que desde el Estado colombiano se concibe a las migraciones y a los migrantes como agentes de desarrollo económico por el supuesto impacto que las remesas tendrían en la macroeconomía colombiana ${ }^{7}$. Al mismo tiempo, el interés otorgado desde la academia a la vinculación entre migración y desarrollo vía remesas, devela como las agendas de investigación están moldeadas por las visiones y divisiones estatales dominantes.

La falta de atención a las dinámicas familiares y de género en los estudios sobre migración colombiana ha comenzado a revertirse hace poco tiempo. Las primeras investigaciones en estos campos se han realizado en los últimos años (Micolta, 2007; Puyana, Motoa y Viviel, 2009; Rivas y Gonzálvez, 2009; Medina Villegas, 2009; Gonzálvez, 2010; Santos Pérez, 2011; Pedone, Echeverri, Gil Araujo, 2012; Gil Araujo, Pedone, Echeverri, 2012; Puyana, Micolta, Palacio, en prensa), algunas de ellas llevadas a cabo por investigadoras afincadas en España, y una minoría han puesto el acento en los y las jóvenes como actores sociales fundamentales de las dinámicas familiares en un contexto migratorio (Carrasquilla Coral y Echeverri Buriticá, 2003; Echeverri Buriticá, 2005, 2010) ${ }^{8}$.

En cuanto a la agenda política colombiana, el tema migratorio aparece con más fuerza a partir de la década de los años noventa del siglo XX, cuando las políticas de vinculación del Estado colombiano con "sus emigrantes" atraen la atención de los diferentes gobiernos. Se establecen derechos políticos como el derecho a votar en elecciones presidenciales otorgado en 1961, el derecho a la doble nacionalidad y a la elección de su propio representante en el congreso (Constitución Política de 1991), y a la elección de senadores a través de la Ley 649 de 2001. Igualmente se destacan la creación de programas especiales para institucionalizar los vínculos a nivel político, económico, social y cultural con el origen y la "promoción de la buena imagen de Colombia en el exterior" por parte de la población migrante, a través del apoyo a proyectos de desarrollo e inversiones, y el fomento de la cultura nacional (Guarnizo, 2006a) ${ }^{9}$. En el año 2003 se crea el Programa Colombia nos une, adscrito
${ }^{7}$ Esta visión del Estado colombiano de los migrantes como agentes de desarrollo también es señalada por Clavijo (2011) en su análisis sobre el Programa Colombia nos Une.

En el marco del estudio de las familias migrantes y el género en Colombia se destacan los siguientes eventos académicos: IV Seminario internacional sobre familia: Desafíos para comprender los procesos familiares en el contexto de la migración internacional, organizado por el Departamento de Estudios de Familia de la Universidad de Caldas, Manizales, abril de 2011; Seminario internacional género migraciones y familias transnacionales, organizado por la Facultad de Psicología y la Facultad de Enfermería de la Pontificia Universidad Javeriana; Escuela de Estudios de Género - GIEG- de la Universidad Nacional de Colombia y la Fundación ESPERANZA, octubre de 2011 en Bogotá y el I Seminario internacional y II Nacional de familias contemporáneas y políticas públicas organizado por la públicas organizado por la agosto de 2012, que tuvo agosto de 2012, que tuvo
dentro de sus paneles uno dedicado a las familias migrantes.

9 Estos programas, algunos de iniciativa privada, comenzaron su implementación hace ya más de tres décadas y sus primeros antecedentes estatales datan de los años setenta con el "Programa de Repatriación "Prograbs". de Cerebros Fugados". En siglo XX, surge el "Programa para la Promoción de las Comunidades Colombianas en el Exterior" (PPCCE, 1996), creado por el Ministerio de Relaciones Exteriores como parte del Plan denominado "Colombia para todos"; la creación de la Red Electrónica Global de Científicos Colombianos (1993) y más recientemente el programa Colombia nos une (2003) liderado también por el Ministerio de Relaciones Exteriores, junto Relaciones Exteriores, junto
a iniciativas privadas como a iniciativas privadas como Colombia' (2003). Sumado a ellos, destaca la iniciativa del gobierno, a través de los Ministerios de Relaciones Exteriores y de Ambiente, Exteriores y de Ambiente,
Vivienda y Desarrollo Territorial, en coordinación con torial, en coordinación con la Cámara Colombiana de la varias entidades financieras nacionales para organizar desde 2005 las llamadas ferias inmobiliarias en el exterior que promueven exterior que promueven a venta de vivienda en ciudades con altas tasas emigratorias en Colombia (Guarnizo, 2006b). 
${ }^{10}$ Algunas cifras reflejan desplazamientos internacionales forzados de la población colombiana en el marco del conflicto armado, la guerra y la violencia en sus múltiples dinámicas 1) Refugiados que cruzan la frontera a países vecinos como Ecuador donde según datos de ACNUR en 2008 había aproximadamente 250.000 personas refugiadas, procedentes casi todas ellas de Colombia. Sin embargo, por la falta de información, el desconocimiento de las leyes que los amparan, el miedo, la in a seguridad, la desprotección que sufrieron de su gobierno, solo 45.000 personas se habían registrado como refugiados ante el gobierno de este país o la delegación de ACNUR (Informe CEAR, 2008); 2) El núm CEAR, peticiones de asilo de colombianos y colombianas en España representa un porcentaje significativo en el total de solicitudes de asilo y refugio que el gobierno español recibe: en 1999 representaron el 7,15\% del total de solicitudes de asilo, en 2000 el $17,2 \%$, en 2003 el $9,7 \%$ y en 2006 el $43,22 \%$. Solicitudes que en su mayoría se resuelven negativamente, donde los expedientes de colombianos no superan el $10 \%$ de resolución positiva descle el año 2000 (Sanabria, 2008). al Ministerio de Relaciones Exterior de Colombia, encargado del diseño y ejecución de la política migratoria y de la coordinación de los organismos que trabajan el tema. En 2009 es aprobada como documento CONPES 3603 la Política Integral Migratoria (PIM) donde las familias migrantes, a pesar de ser referenciadas como un "tema que merece especial atención", se determinan como "objeto de mayor profundización y sustentación empírica", en tanto los "diagnósticos son insuficientes para la definición de acciones en materia de género y familia" (Conpes 3603, 2009). No hay ninguna referencia en el documento al transnacionalismo familiar.

En esta línea, las migraciones y los sujetos migrantes han sido pensados desde el Estado colombiano como agentes de desarrollo, consumidores o inversionistas (Clavijo, 2011), destacándose el envío de remesas como una de las principales razones que llevan a los diferentes gobiernos a buscar mantener una relación con los colombianos residentes en el extranjero, que, además, por el derecho de voto, se constituyen en una importante fuerza política para los diferentes representantes o partidos políticos (Guarnizo, 2003, 2006a). Esta forma de concebir las migraciones oculta y negar, entre otras cosas, el conflicto armado y la violencia sociopolítica como causa de las migraciones internacionales, dejando por fuera del programa Colombia nos une, principal organismo encargado de la gestión política de las migraciones internacionales en Colombia, a los refugiados y asilados (Clavijo, 2011) ${ }^{10}$.

No. Nosotros la verdad que, nosotros digo: "Colombia nos une", nosotros somos bastante como cuidadoso con ese tema [...] porque nuestra población objetivo no es el refugio [...] Es un tema que es prácticamente del despacho de la viceministra. Incluso ahora es importante. Con la nueva administración van a hacer una nueva comisión asesora, y no sé que [...] Pero ahí nosotros no nos metemos. Digamos, que es un tema que de ahí no pasa. Y no, no se relaciona cuando hablamos con cancillerías (Funcionaria Colombia nos une, Bogotá, 2010).

En este escenario, el aumento de la presencia femenina en las corrientes migratorias colombianas que desde principios del siglo XXI llegaron a España disparó un discurso social, académico y político que fue configurando a las familias migrantes como problema social. Nuestro trabajo de campo en Risaralda -área de mayor emigración femenina hacia España- y en Bogotá reveló los idearios que alimentan los discursos públicos: la salida de las mujeres provoca la "desintegración familiar" y trae "disfuncionalidades" a 
las familias migrantes. Como lo analizó Pedone $(2006,2008)$ para el caso ecuatoriano, también en Colombia el incremento de la migración de mujeres como primer eslabón de la cadena migratoria fue acompañado por discursos que han ido configurando una visión del proceso migratorio como origen de la desintegración familiar y del abandono de los hijos e hijas de las familias migrantes.

[El discurso oficial en Risaralda es que] La familia está acabando [...] Si hablas con el gobernador, con el Secretario del Gobierno, que es uno de los abanderados, entonces te dicen que es que la familia se está desintegrando (Experto en migraciones y política migratoria, Pereira, 2010).

Aquí, aquí de todo hay, pero no, es que uno no puede pervertir ni contribuir a rotular una comunidad que bien rotulada está [...] Y que si [las mujeres] se fueron fue por física necesidad. Que si se fueron fue a buscar cómo darle el almuerzo y el desayuno a sus hijos, que fuera de eso hay madres que se fueron y que nunca se acordaron que tenían hijos, hombre, eso es cierto, pero no es la generalidad (Técnica trabaja con migrantes, Pereira, 2010).

Estas imágenes que estigmatizan, construidas en la "natural" conexión entre migración femenina y disfuncionalidades familiares se reflejan en los lineamientos de la Política Integral Migratoria (PIM) al afirmar que "El denominado fenómeno de la feminización de las migraciones y su impacto en la familia, es un tema que merece especial atención". En el documento aparece una clara preocupación por el "rol de la mujer y su transformación con la migración", los "impactos en las mujeres que se quedan y sus hijos" y sobre todo los "cambios en el modelo de familia" que trae la migración de las mujeres colombianas. Como contracara de la problematización de las migraciones femeninas, los varones están ausentes en las cavilaciones de la Política Integral Migratoria cuando se refieren a las familias migrantes. El enfoque de género se traduce y reduce a colocar a las mujeres migrantes en el centro de la política, en tanto son consideradas responsables naturales del bienestar de las familias y de los cuidados de la prole, por lo cual se sugiere "elaborar un plan de acción con el apoyo del Instituto Colombiano de Bienestar Familiar (ICBF) y la Consejería Presidencial para la Equidad de la Mujer" (Documento Conpes 3603, 2009:50): 
El denominado fenómeno de la feminización de las migraciones y su impacto en la familia, es un tema que merece especial atención. Pese a que existen estudios al respecto, estos deben ser objeto de mayor profundización y sustentación empírica, particularmente en nuestro caso. Dada la complejidad del mismo, es necesario profundizar el análisis que dé cuenta de los siguientes aspectos, entre otros, no todos específicos del fenómeno migratorio sino de cambios contemporáneos: el rol de la mujer y su transformación con la migración; la participación femenina en el mercado de trabajo y cambio de roles; desigualdades de género en el mercado de trabajo; conexión entre los fenómenos de desigualdad de género de la sociedad emisora de la migración y la sociedad receptora de la misma; impactos en las mujeres que se quedan, sus hijos y cambios en el modelo de familia. Hay múltiples razones que van más allá de lo económico en esta problemática, las mujeres migrantes no son un bloque homogéneo, ello determina la complejidad en la definición de las políticas públicas en cada contexto (Documento Conpes 3603, 2009:50).

En el marco de la configuración de vínculos familiares transnacionales, esta visión problematizadora de la migración femenina recae igualmente sobre los hijos e hijas de las madres migrantes, que han sido denominados como "Los hijos de las remesas"11. En este sentido, a la migración de mujeres-madres se les adjudica también la responsabilidad por el aumento de embarazos adolescentes, el bajo rendimiento escolar y la delincuencia de los grupos juveniles. Aparece en el entorno religioso (católico preferentemente), político y educativo la vinculación entre migración y orfandad. Como ejemplo de lo que aquí señalamos, la Procuraduría General publicó un informe sobre los hijos de la migración titulado "Hijos huérfanos de padres vivos"12, que recibió una dura crítica de algunos sectores académicos.

Aquí [en Pereira], si hay prostitución entre los jóvenes es por la migración. Si hay pandillas, es por la migración. Si hay consumo de drogas, es por la migración. El cuento de los huérfanos de padres vivos. Y además es horrible. Es horrible, y así se refieren a ellos. Toda esa estigmatización al niño, además cuando se dice huérfano, se dice huérfano de madre. Por supuesto, ser huérfano de madre, el padre no hay problema, son más las mujeres que han abandonado a sus hijos.

${ }^{11}$ Revista Semana, 21 de noviembre de 2004.

${ }^{12}$ El Tiempo, 12 de enero de 2009.
El cuento de que se están gastando la plata [...] de que sí, de que están gastando la plata en consumo, y en consumo. Claro!!! Como se gasta 
en lo fundamental los salarios, la gente trabaja para comer isi? Pero entonces de ahí pasan a que entonces es que supuestamente el consumo es tenis Nike, inclusive le tienen marca (Experto en migraciones y política migratoria, Pereira, 2010).

Sin embargo, y a pesar de que en la Política Integral Migratoria las familias migrantes son referenciadas como un "tema que merece especial atención", el accionar político en torno a la migración (expresado en programas y proyectos financiados con los recursos públicos en los niveles departamental y nacional) pivota actualmente entre los problemas que genera el retorno de emigrantes -sobre todo un retorno masculino que señala a los varones retornados como responsables de agravar el problema de desempleo en algunas regiones- y la necesidad imperiosa del Estado de captar las remesas económicas y sociales de los y las migrantes. El relato de una funcionaria del programa Colombia nos une denota la preocupación del gobierno central por el retorno de los migrantes calificados, pero sobre todo por "gestionar la promoción de incentivos en los diferentes sectores que faciliten la transferencia de conocimientos de colombianos en el exterior altamente calificados" (Documento Conpes 3603, 2009:69), sin responder a las necesidades de las familias migrantes.

Nosotros, nuestro Conpes 3603, dice: hay que hacer algo para los colombianos altamente calificados. Entonces ese algo es un proyecto que estamos haciendo [...] Se está haciendo precisamente un ejercicio de información de incubadoras del conocimiento en tres países de América Latina: Uruguay, Argentina y Colombia [...] Entonces cogen los recursos de investigación y dicen: este año por lo menos con recursos propios únicamente vamos a trabajar ese tema, altamente calificados [...] Hay que reconocer una falencia que tiene el programa, que es el tema de género y familia. O sea, tenemos muy buenas intenciones, pero si nos dicen ahorita, venga ¿usted qué ha hecho? yo le digo, de verdad no hemos hecho nada. De verdad no hemos hecho nada (Funcionaria programa Colombia nos une, Bogotá, 2010).

El tema [de las familias migrantes] empieza a considerarse, pero programas específicos, yo no veo ninguno. Se considera y empieza a ser una preocupación, movida por algunos estudios muy elementales, muy incipientes. Pero se empieza a poner (Experto en migraciones y política migratoria, Pereira, 2010). 
En resumen, el debate público sobre las familias migrantes en Colombia emerge bajo problematizaciones donde persiste una visión ideologizada de 'la familia' como organización social 'básica` basada en un modelo tradicional que acuñó la iglesia católica a mediados del siglo XVI y que aún forma parte importante de la doctrina acerca del matrimonio y la familia (Muñoz, 2006). Esta mirada afianza los discursos que en origen condenan la migración de las mujeres y las ubica como las principales responsables por la "desintegración familiar" y el "abandono de los hijos", siendo el blanco de la estigmatización y el desprestigio familiar y social. La Política Integral Migratoria reproduce en sus lineamientos este discurso hegemónico sin reconocer la heterogeneidad de la población migrante internacional colombiana y la diversidad de condiciones, proyectos y trayectorias de las familias migrantes.

\section{REFLEXIONES FINALES}

En el contexto europeo, las políticas de migración familiar están operando como instrumentos de control, restricción y selección de inmigrantes. Los motivos esgrimidos para justificar el endurecimiento de la política de migración familiar giran en torno a la problematización de la presencia inmigrante en términos de integración, la defensa del Estado de bienestar y, últimamente, la crisis económica. En este marco, el carácter aparentemente inclusivo de la lógica de la integración muestra su vertiente discriminatoria y excluyente. En España, la migración familiar, hasta hace poco tiempo ignorada en el discurso político y en las estadísticas, en el marco de la crisis económica ha devenido tema de debate público. La última modificación de la Ley de Extranjería impone nuevas limitaciones al derecho de reagrupación familiar a los ascendientes. Desde las políticas migratorias el ideario de familia se reduce a la familia nuclear (padre-madre-hijos menores), y se concibe a las mujeres como facilitadoras del proceso de integración y como "puente entre culturas". Desde esta perspectiva se refuerza el rol de las mujeres como reproductoras, cuidadoras y transmisoras/inculcadoras de valores, no reconociendo su desempeño como productoras de recursos económicos para el sostén de la familia en un contexto migratorio transnacional, como ocurre en el caso de gran parte de las migrantes latinoamericanas.

En Colombia, la salida de mujeres como primer eslabón de la cadena migratoria ha puesto en evidencia los proyectos migratorios de carácter familiar. A comienzos del siglo XXI la feminización de las migraciones generó discursos estigmatizadores que asocian la emigración de las mujeres 
al abandono de los hijos, a la desintegración familiar y a otras supuestas "disfuncionalidades" en el seno de las familias. En este contexto los niños, niñas y jóvenes de las familias migrantes son visibilizados como sujetos con comportamientos "desviados" y "delictivos": pandillas juveniles, consumo de alcohol y drogas, consumo superfluo, aumento del índice del embarazo adolescente, que en última instancia son responsabilidad de las madres. Estos planteamientos se sustentan en visiones que naturalizan el papel de las mujeres como cuidadoras y reservan a los varones el rol de proveedores del sustento económico.

Las políticas públicas del Estado colombiano dirigidas a las familias migrantes están también permeadas por estas concepciones hegemónicas. Así, la diversidad de sus miembros: mujeres, varones, niños, niñas, jóvenes, abuelos, abuelas, cuidadores, cuidadoras, siguen ausentes de las políticas migratorias a pesar de los llamados de atención de algunas investigaciones producidas en el país. Por el contrario, los principios de la Política Integral Migratoria parecería que recogen principalmente los estigmas que penden sobre las familias involucradas en la migración.

Si bien el proceso de construcción del vínculo entre migración y familia como problema social tiene antecedentes y rasgos distintivos en España y en Colombia, también es posible localizar similitudes entre los distintos contextos. El protagonismo femenino en las cadenas migratorias hacia España ha puesto en cuestión los papeles tradicionalmente asignados a varones y mujeres en el cuidado familiar y en la crianza de los hijos e hijas. Estos cambios (muchas veces temporales) en las formas de organización y en los roles de género al interior de los grupos domésticos han alentado la circulación de discursos que culpabilizan a las mujeres por el impacto de la migración en las estructuras familiares, al tiempo que difuminan el fundamental aporte de estas mujeres al bienestar, no solo de sus familias, sino también de sus países de origen.

Las concepciones tradicionales sobre el ejercicio de la maternidad refuerzan la ausencia de debate acerca de la responsabilidad de los varones (migrantes o no) en el ámbito familiar y omiten el papel de las mujeres migrantes como proveedoras de recursos para sus familias, pero además como principales organizadoras del cuidado transnacional. La estigmatización de la migración de mujeres-madres es lo que a su vez promueve la circulación de visiones descalificadoras sobre los hijos e hijas de la migración. Tanto en origen como 
en destino, niños y niñas de familias migrantes suelen ser pensados como víctimas del abandono de sus progenitores (responsables del fracaso escolar), mientras los jóvenes son convertidos en problema social.

En general, los discursos hegemónicos no reconocen la organización del cuidado en un contexto familiar transnacional, como el ensayo de formas de vida familiar alternativas que provocan reacomodamientos en las relaciones de género y generacionales. Por el contrario, continúa presente la idea de que estos arreglos constituyen una desviación al ideal de familia con un varón proveedor y una mujer cuidadora, y con una relación materno-filial materializada en un espacio nacional común y compartido. Si es en el lugar de origen, mejor. Tanto para el país de emigración como de inmigración, y probablemente también para los migrantes, ese es el territorio de natural pertenencia. Sin embargo, los retornos emprendidos en el contexto de la crisis económica están cuestionando estas idealizaciones y convocan nuevos interrogantes sobre las variadas articulaciones entre migración, familia, género y generación.

\section{BIBLIOGRAFÍA}

Actis, W. (Colectivo IOE). (2009). La migración colombiana en España: ¿salvados o entrampados? En: Revista de Indias Vol. LXIX No 245.

Agrela Romero, B. (2009). De los significados género e inmigración (re)producidos en las políticas sociales y sus consecuencias para la acción e integración social. En Cachón, L. y Laparra, M. (comps.) Inmigración y Políticas Sociales. Barcelona, Bellaterra.

Aparicio, R.; Giménez, C. (2003). Migración colombiana en España. Organización internacional para las migraciones, Naciones Unidas y Embajada de Colombia en España, Madrid.

ASOCAMBIARIA. (2004). Encuesta a beneficiarios de remesas de trabajadores en agencias de instituciones cambiarias en Colombia. Bogotá.

Cachon, L. (2003). Inmigrantes jóvenes en España, sistema educativo y mercado de trabajo. Instituto de la Juventud, Ministerio de Trabajo y Asuntos Sociales, Madrid.

Cárdenas, M.; Mejía, C. (2006). Migraciones internacionales en Colombia: ¿qué sabemos? Documento de Trabajo No 30, Fedesarrollo, Bogotá. 
Carrasquilla, M. C.; Echeverri, M. M. (2003). Los procesos de integración social de los jóvenes ecuatorianos y colombianos en España: un juego identitario en los proyectos migratorios. Estudios de Juventud, 60: 89-100. Madrid.

Clavijo, J. (2011). La política migratoria colombiana en el periodo 2002 -2010: el programa Colombia nos une (CNU). Universidad Nacional de Córdoba Centro de Estudios Avanzados. Tesis Maestría en relaciones internacionales (Inédita).

Comisionn Española de Ayuda al Refugiado (CEAR) (2008). La situación de los refugiados en España, informe 2008, Madrid.

Consejo Nacional de Política Econ6mica y Social. Departamento Nacional de Planeación (2009). Documento Conpes 3603. Política Integral Migratoria.

Echeverri Buritica, M. M. (2005). Fracturas identitarias: circunstancias migratorias y procesos de integración social de los jóvenes colombianos en España. Migraciones Internacionales 3, 1: 141-164. México.

Echeverri, M. M. (2010). "Son diez horas de viaje y cinco años que te meten encima". Proyectos, identidades y vínculos transnacionales de los y las jóvenes colombianas en España. Tesis doctoral. Universidad Complutense de Madrid. Inédita.

Garay, L. J.; Rodríguez, A. (2005). La emigración internacional en el área metropolitana centro occidente Colombia. Caracterización socioeconómica de la población emigrante y evaluación del impacto de las remesas internacionales. Ministerio de Relaciones Exteriores - República de Colombia, OIM, Bogotá.

Garay, L. J. (2006). El colectivo colombiano residente en la comunidad de Madrid: Caracterización socioeconómica, inserción laboral e integración social. En Colombia nos une. Memorias II Seminario sobre migración internacional colombiana y la conformación de comunidades transnacionales. Ministerio de Relaciones Exteriores, Bogotá

Garay, L. J.; Medina, M. C. (2007). La migración colombiana a España. El capítulo más reciente de una historia compartida. Ministerio de Trabajo e Inmigración, Observatorio Permanente de Inmigración, Madrid.

Gil Araujo, S. (2010a). Las argucias de la integración. Políticas migratorias, construcción nacional y cuestión social. IEPALA, Madrid. 
Gil Araujo, S. (2010b). Las políticas de migración familiar en Europa. El gobierno de la inmigración a través de las familias. En Agustín García, A.; Gadea, M. E. y Pedreño, A. (coords.). Tránsitos migratorios: Contextos transnacionales y proyectos familiares en las migraciones actuales. Universidad de Murcia, Murcia.

Gil Araujo, S.; Pedone, C. y Echeverri. M. M. (2012) Migración y vida familiar entre España y América Latina. Imbricaciones entre las políticas migratorias y las formas de organización de las familias migrantes ecuatorianas y colombianas en España, XI Jornadas Nacionales de Historia de las Mujeres y VI Congreso Iberoamericano de Estudios de Género, Universidad Nacional de San Juan, 12-14 de septiembre, San Juan.

Gonzálvez, Herminia (2010) Migración colombiana, género y parentesco: La organización social de los cuidados. Tesis doctoral (inédita). Universidad de Granada, Granada.

Guarnizo, L. E. (2003). La migración transnacional colombiana: implicaciones teóricas y prácticas. Memoria seminario sobre migración internacional colombiana y la conformación de comunidades transnacionales. Ministerio de Relaciones Exteriores, Colombia nos une, Bogotá.

Guarnizo, L. E. (2006a). Migración, globalización y sociedad: Teorías y tendencias en el siglo XX. En: Ardila, G. (ed.). Colombia: Migraciones, transnacionalismo y desplazamiento. CES, Bogotá.

Guarnizo, L. E. (2006b). El estado y la migración global colombiana. Migración y desarrollo. Primer semestre.

Herrera, G., (2011). La familia migrante en las políticas públicas en Ecuador: De símbolo de la tragedia a objeto de intervención. En Feldman-Bianco, B. et al. (comps.). La construcción social del sujeto migrante en América Latina. Prácticas, representaciones y categorías. CLACSO-FLACSOUniv. Alberto Hurtado, Quito.

Instituto Nacional de Estadística (2009). Notas de Prensa. Avance del Padrón municipal a 1 de enero de 2009 (datos provisionales). http://www.ine.es/prensa/np551.pdf. Consultado 18/06/2009.

Khoudour, D. (2007). ¿Por qué emigran los colombianos? Un análisis departamental basado en el censo del 2005. Revista de Economía Institucional, 9 (16).

Kraler,A; Kofman, E; Kohli, M. and Schmoll, C. (eds) (2011) (cords.)Gender, Generations and the Family in International Migration.Amsterdam: IMISCOE Research-Amsterdam University Press. 
La Spina, E. (2012). Los usos de la metodología científica en el control de la "falsa" inmigración hacia España: una perspectiva crítica. Ponencia VII Congreso migraciones internacionales en España. Movilidad Humana y Diversidad Social. Bilbao, España.

Medina Villegas, M. C. (2009). Los ausentes están siempre presentes. Una aproximación interpretativa de la experiencia materno-filial transnacional entre España y Colombia. Tesis doctoral (inédita). Universidad Complutense de Madrid.Madrid.

Micolta, A. (2007) "Inmigrantes colombianos en España. Experiencia parental e inmigración". Revista Latinoamericana de Ciencias Sociales Niñez y Juventud, 5 (1).

Ministerio de Relaciones Exteriores. (2006). II Seminario sobre migración internacional colombiana. Ministerio de Relaciones Internacionales, Bogotá.

Mojica, J. A. (2009). Zona cafetera tiene 50 mil niños huérfanos, de padres vivos. El Tiempo, 12 de enero de 2009. Disponible en:http://www.eltiempo.com/archivo/documento/MAM-3265122. Consultada enero de 2012.

Muñoz, G. (2006). La comunicación en los mundos de vida juveniles: hacia una ciudadanía comunicativa. Tesis doctoral en ciencias sociales. Centro de estudios avanzados en niñez y juventud, Universidad de Manizales, CINDE, Manizales.

OIM. (2005). Memorias del Seminario migración internacional, el impacto y las tendencias de las remesas en Colombia. www.oim.org.co.

OIM. (2007). Comunidades colombianas en el exterior y su papel en el desarrollo. Colombia. WWW.oim.org.co.

OIM y DANE. (2005). Metodología encuesta sobre emigrantes internacionales y remesas en el Área Metropolitana Centro Occidente - AMCO. Bogotá.

Pedone, C., Agrela, B., Gil Araujo, S. (2012) "Políticas públicas, migración y familia: una mirada desde el género", Papers. Revista de Sociología, vol. 97, №3.

Pedone, C.; Echeverri, M. M.; Gil Araujo, S. (2012). Familias que trascienden fronteras. Formas de organización familiar transnacional de la población migrante colombiana y ecuatoriana en España (en tiempos de crisis global). Ponencia VII Congreso migraciones internacionales en España. movilidad humana y diversidad social. Bilbao, España. 
Pedone, C. (2008). "'Varones aventureros' vs. 'madres que abandonan': Reconstrucción de las relaciones familiares a partir de la migración ecuatoriana". Revista Interdisciplinar da Mobilidad Humana. Centro Scalabriniano de Estudos Migratórios, Brasilia.

Pedone, C.; Gil, S. (2008). "Los laberintos de la ciudadanía. Políticas migratorias e inserción de las familias migrantes latinoamericanas en España". Revista Interdisciplinaria de la Movilidad Humana. Brasilia: Centro Scalabriniano de Estudos Migratórios.

Pedone, C. (2006). Estrategias migratorias y poder. 'Tú siempre jalas a los tuyos'. ABYA-YALAPMCD-AECI.Quito.

Programa bienvenido a casa (2009), Portal de la Ciudad de Bogotá. En línea. Disponble en: portal http://www.bogota.gov.co/portel/libreria/php/01.3010.html), Consultada en Agosto 2010.

Puyana, Yolanda, Julieth Motoa y Adriana Viviel. 2009. Entre aquí y allá. Las familias colombianas transnacionales. UE-Universidad Nacional de Colombia-Fundación Esperanza, Bogotá.

Puyana, Y.; Micolta, A.; Palacio, M. C. (Editoras). (En prensa). Familias colombianas en situación de transnacionalidad. Experiencias, cambios y retos.

Rivas, A. M.; Gonzálvez, H. (2009). Familias transnacionales colombianas. Transformaciones y permanencias en las relaciones familiares y de género. Cataratas, Barcelona.

Rovetta Cortés, A. I. (2011). Políticas de integración y familias migrantes en la comunidad de Madrid. Ponencia presentada en el III Congreso anual de la REPS. Los actores de las políticas sociales en contextos de transformación. Panel 1: Políticas sociales y trabajo social transnacional: las organizaciones de lo social más allá de las fronteras del Estado, los actores y la política de cooperación.

Sanabria, H. (2008). Los inmigrantes colombianos en España: Trayectoria y perspectivas. Documento de Trabajo No 35/2008. Real Instituto Elcano, Madrid.

Santos Pérez, M. L. (2011). Mujeres ausentes y cabezas de familia: Realidades sociales y económicas de las familias transnacionales constituidas entre Colombia y España, Serie Avances de Investigación, № 63. CeALCI-Fundación Carolina., Madrid.

Sayad, A. (2000). "Imigraçao de trabalho e imigraçao de povoamento", Travessia. Revista do migrante, especial (24-26). 
Secretaría Estatal para la Inmigración y Emigración. (2007). Plan Estratégico de Ciudadanía e Integración 2007-2010. Ministerio de Trabajo e Inmigración, Madrid.

Secretaria Per a la Immigraci6. (2010). Plan de Ciudadanía e Inmigración 2009-2012. Departamentd'Acció Social i Ciutadania, Generalitat de Catalunya, Barcelona.

UN-INSTRAW, OIM (2007). Género y remesas. Migración colombiana del AMCO hacia España, Bogotá.

Villegas, N. 2004. Los hijos de las remesas. Revista Semana, noviembre 25. http://www. conexioncolombia.com. Consultada abril 2006. 